\title{
¿El hombre nuevo?: Moral revolucionaria guevarista y militancia femenina. El caso del MIR
}

\section{¿The new man?: Moral revolutionary guevarista and female militancy. The case of the MIR}

\author{
Tamara Vidaurrázaga Aránguiz \\ Estudiante doctorado Universidad de Chile \\ tamaravidaurrazaga@yahoo.es
}

\begin{abstract}
SÍNTESIS
Las organizaciones de la nueva izquierda, nacidas en Latinoamérica luego de la revolución cubana, siguieron la moral guevarista y creyeron en la conformación del hombre nuevo. Nos preguntamos en el presente artículo si este concepto incluyó a las mujeres y consideró el ámbito de la vida privada, para lo cual presentaremos el caso específico de las mujeres del MIR.
\end{abstract}

\begin{abstract}
The organizations of the New Left, born in Latin America after the Cuban revolution, they followed Guevara's moral and believed in the shaping of the New Man. In this article, we wonder if this concept included women and considered the area of private life.We talk about the specific case of women that were MIR's militants.
\end{abstract}

Palabras clave: guevarismo, moral, género, izquierda revolucionaria. Keywords: guevarismo, moral, gender, left revolucionary.

En los 60 y 70 nacieron en Latinoamérica organizaciones de izquierda revolucionaria llamadas la nueva izquierda: marxistas y leninistas, agregaron a su ideario el guevarismo heredado de la revolución cubana, basado en la idea de que la revolución posibilitaría no solo cambios sociales sino también el nacimiento del hombre nuevo. 
A pesar de que la revolución cubana, y especialmente las organizaciones nacidas posteriormente a ella, se caracterizaron por la mayor participación femenina en términos cualitativos y cuantitativos, el concepto de hombre nuevo es originado en la mente de un hombremasculino, en el contexto masculino de la guerra de guerrillas. Un lugar donde las mujeres y lo femenino quedaban excluidos porque históricamente la guerra es un espacio masculino y el guerrero el rol preponderante de las masculinidad, como lo asegura Simone de Beauvoir (1987). Es a través del guerrero -que se amolda perfectamente con las características del héroe- que el hombre trasciende la importancia de la vida -asociada a lo femenino- al ser capaz de entregarla en pos de una causa más importante que la vida misma.

Pero en las luchas armadas latinoamericanas también hubo mujeres, mujeres que a pesar de serlo soñaron con convertirse en el hombre nuevo del Che Guevara, un personaje ejemplar, sacrificial y heroico. Un sujeto que estaba dispuesto a dejar todas las comodidades y los vínculos nacidos en el mundo de lo personal -los llamados placeres pequeño burgueses- con tal de luchar por la causa colectiva y abstracta de la revolución. El hombre nuevo nunca contempló entonces lo que para las mujeres militantes significaría asumir estos desafíos construidos para militantes varones; tampoco contempló lo que implicaría para la vida privada de quienes militaban, especialmente de las mujeres que -según el mandato del sistema sexo género (ssg) hegemónico- deberían poner la mayor parte de su esfuerzo e interés en que este espacio de sus vidas sea exitoso, además de ser evaluadas socialmente por ello.

¿Cómo fue en este contexto la militancia femenina en las organizaciones de lucha armada latinoamericana originada en los 60-70? ¿Cuáles fueron las diferencias que las protagonistas de esta militancia observaron en su momento o en el recuerdo posterior? ¿Estas posibles diferencias desataron tensiones en ellas? ¿Cómo se enfrentaron a ellas?

En el presente artículo presentaremos las características del guevarismo y especialmente del llamado hombre nuevo, y nos preguntaremos cuánto de esto tiene sesgos patriarcales que las mujeres militantes asumieron, no solo al dejar fuera a las propias mujeres, sino también al desestimar la importancia del espacio privado o personal, hegemónicamente vinculado con lo femenino. Luego revisaremos 
el caso específico de las militantes del MIR chileno, a través de testimonios, entrevistas y documentales revisados; y de entrevistas de vida realizadas a tres militantes en una investigación que realicé previamente y publicada por primera vez en el 2006 llamada Mujeres en Rojo y Negro.

\section{Moral revolucionaria}

Estas mujeres militantes estaban insertas en contextos sexo genéricos disímiles: entre otros, el de las mujeres tradicionales de la sociedad latinoamericana de la época que vivieron, y el que existía como filosofía de vida paralela dentro de los movimientos revolucionarios, que se guiaban por lo que llamaremos moral revolucionaria, y que en la llamada nueva izquierda recogía principalmente los legados del Che Guevara respecto de la teoría y la práctica del revolucionario y la conformación del llamado hombre nuevo. El hombre nuevo, siempre dicho en masculino, aun cuando el mismo Che compartió la guerrilla con mujeres como Tamara Bunker, y una de las características de los movimientos armados de la nueva izquierda latinoamericana de los 60, 70,-diferente a los partidos políticos tradicionales- fue el alto número de mujeres participantes. Entendemos esta moral revolucionaria como descendiente de la ideología marxista leninista, y contraria a la ideología burguesa predominante en la sociedad capitalista (Castro, 237).

Según los pensamientos guevaristas, no había que esperar entonces a que los cambios sociales y económicos cambiaran por sí solos a los individuos, sino que ellos debían poner su empeño en ser coherentes con el proceso de transformación y a su vez promoverían un mayor cambio en el sistema productivo toda vez que trabajarían por el sentido de responsabilidad revolucionario y no por el dinero y el goce individual que éste les daría (Martínez, 54).

Señalaba el líder guerrillero al respecto: “El socialismo económico sin la moral comunista no me interesa. Luchamos contra la miseria, pero al mismo tiempo luchamos contra la alienación (...) Si el comunismo descuida los hechos de conciencia puede ser un método de repartición, pero deja de ser moral revolucionaria" (en Martínez, 68). 
Como planteaba el Che, la transformación de los individuos no sería pareja, habría una vanguardia que daría el ejemplo hacía el resto de la sociedad y demostraría cómo se puede actuar coherentemente con un pensamiento revolucionario (4).

Para las organizaciones guevaristas de latinoamericanas, como el MIR, estaba claro que la vanguardia eran ellos. No solo la vanguardia en cuanto a liderar la lucha política y armada, sino también la vanguardia que lideraba la transformación desde el hombre burgués al hombre nuevo.

Es la nueva moral revolucionaria la que daría lugar al llamado hombre nиеvo. El hombre nuеvo -al que estas guerrilleras quería emular, aun cuando fuera imposible convertirse en un hombre- era un sujeto sumamente ejemplar, sacrificial y heroico.

Ejemplar en tanto el sujeto protagonista de la guerrilla debía ser el mejor o la mejor en todo. Al decir todo, evidentemente se referían al plano de lo público porque lo privado ni siquiera estaba en cuestión: el mejor en los estudios políticos, en la práctica armada, en el trabajo, en lo que fuera que se emprendiera en la vida y donde se pudiera ser un ejemplo para otros, que reconocerían en esa persona alguien a quien emular. El deber convertido en placer o como señala el Che al respecto:

...la ejemplaridad es una avanzada hacia el comunismo; ella registra los sucesivos parámetros que permiten medir al hombre nuevo 'que va naciendo', 'que estamos creando', no a un mítico hombre nuevo que encontraremos al final de los tiempos. Trata de cambios en la totalidad del individuo, mediante los cuales sus acciones, su intelección y sus afectos y sentimientos se entregan cada vez más a la colectividad y menos al interés individual, y el deber se va tornando paulatinamente en satisfacción y en placer (El pensamiento revolucionario, 1988).

Sacrificial en tanto estaba dispuesto a darlo todo por la revolución, y a renunciar en pos de este ideal a todos los goces humanos, incluida la familia y hasta la propia vida. Esta idea de que la vida era una mera herramienta para la revolución es constante en los textos del Che y en la moral revolucionaria, el grito patria o muerte es una evidencia de ello. Dice el francés Regis Debray sobre la vida del revolucionario: "Jugarse el todo por el todo quiere decir; que una vez 
alzados en la montaña, los combatientes libran una guerra a muerte, que ya no admite treguas, retrocesos o componendas. Vencer es aceptar, desde un principio, que la vida no es el bien supremo del revolucionario" (15 subrayado en el original). Respecto del sacrificio, el propio Che Guevara escribió sobre el individuo cubano puesto en el escenario de la revolución:

El individuo de nuestro país sabe que la época gloriosa que le toca vivir es de sacrificio; conoce el sacrificio. Los primeros lo conocieron en la Sierra Maestra y donde quiera que se luchó; después lo hemos conocido en toda Cuba. Cuba es la vanguardia de América y debe hacer sacrificios porque ocupa el lugar de avanzada, porque indica a las masas de América Latina el camino de la libertad plena (7).

Heroico en tanto el ideal revolucionario otorgaba un valor anteriormente desconocido que radicaba en la convicción de que el proyecto revolucionario era mucho mayor que los proyectos personales, y por tanto se actuaba con heroísmo dadivoso aun cuando no se fuera especialmente heroico en la cotidianidad, porque el llamado de la nueva moral y la construcción del hombre nuevo así lo exigía. La cobardía era un mal molesto para cualquier revolucionario, una tara difícil de aceptar en medio de la batalla.

Este hombre nuevo sería capaz de sentir una injusticia cometida contra cualquiera en cualquier parte del mundo, como dijo el Che en su texto "El hombre y el socialismo. Esta idea de amor, pero de amor abstracto hacia la humanidad estaba presente en el discurso del Che: "Déjeme decirle, a riesgo de parecer ridículo, que el revolucionario verdadero está guiado por grandes sentimientos de amor. Es imposible pensar en un revolucionario auténtico sin esta cualidad" (7).

Lo heroico tiene directa relación, según Todorov, con el amor hacia el ideal abstracto más que a personas concretas; es esa abstracción lo que importa más que todo, más incluso que la vida misma (18).

\section{La guerrillera}

Las mujeres se acomodaron sin cuestionar a estos conceptos. Suponían que el término "hombre" las incluía, y no vieron reparos en 
que se les pidiera lo mismo que a sus compañeros varones: el mismo heroísmo, el mismo sacrificio, la misma ejemplaridad. Suponían que el hombre nuevo era un sujeto neutro, aún cuando había sido construido por un hombre, con una visión de la revolución donde lo masculino-público primaba porque era lo que dominaba en la vida particular de ese hombre y del general de los hombres en el sistema sexo género dominante de la época.

Estas características fueron emuladas por las mujeres guerrilleras y al mismo tiempo cuestionadas -entonces o posteriormentepor algunas de ellas. Gioconda Belli, guerrillera y líder del gobierno sandinista, escribe al respecto en su novela de ficción sobre un país imaginario El país de las mujeres:

La cobardía era señal de salud en Faguas, donde por años, el culto al heroísmo había animado a la gente a morirse por la patria. El martirologio era una patología que se repetía de generación en generación. Los muertos eran respetables, pero los vivos valían un carajo (...) Los soldados conocidos y hasta los desconocidos siempre tenían los mejores monumentos, las llamas eternas, los obeliscos, los arcos del triunfo. Las mujeres puja y puja alumbrando chavalos, haciendo de tripas corazón, criando y alimentando a esos hombrecitos tan prestos a morir, y a duras penas les hacían aquellos monumentos desgarbados y patéticos que acababan en los parques más aburridos del mundo (2010).

Sin duda el ingresar al mundo de las armas, históricamente masculino, y entrar a la dinámica de la moral revolucionaria guevarista; también construida sobre las bases de la masculinidad hegemónica, provocaron desafíos en mujeres que venían de un sistema sexo género hegemónico, en el que las expectativas de lo femenino se vinculaban a lo tradicional. Mujeres -con el mandato de un femenino tradicional- puestas en un espacio político y armado; históricamente masculino e incluso masculinizante, fue una característica de estas guerrilleras, puesto que las guerras y guerrillas son un espacio históricamente masculino que estas mujeres ocupan distorsionándolo (Vidaurrázaga, 1996).

En la cita, Belli evidencia cómo los valores masculinos de la guerra ensalzan la muerte -masculina- por sobre la vida-femenina-. Y, aunque la vida es esencial para la humanidad en tanto se requiere 
prolongar la especie en el tiempo, la capacidad de darla no ha sido tan valorada en el sistema sexo género dominante, como la de quitarla. Simone de Beauvoir plantea que el dar vida es visto como un hecho natural, que sucede en la inmanente vida de la mujer. Quitar la vida, y arriesgarla en este juego, es -en cambio- altamente reconocido, ya que significa trascender a la inmanencia, dejar el existir para entrar al ser que expresa la capacidad de tomar las riendas de la propia vida más allá de lo dado naturalmente. Es tomar la libertad humana para elegir un proyecto, que en este caso es arriesgar la vida y estar dispuesto a quitarla:

Su actividad tiene otra dimensión, que le da su suprema dignidad, pero a menudo es peligrosa. Si la sangre no fuese más que un alimento, no tendría mayor valor que la leche, pero el cazador no es un carnicero, pues corre peligros en su lucha contra los animales salvajes. El guerrero pone en peligro su propia vida para aumentar el prestigio de la horda, del clan al cual pertenece. Y, de ese modo, prueba brillantemente que la vida no es el valor supremo para el hombre, sino que debe servir a fines más importantes que ella misma (De Beauvoir, 109).

Todorov plantea que para el héroe la muerte es superior a la vida porque lo que está en el centro es el ideal abstracto y no las personas concretas: "Para el heroísmo, la muerte es un valor superior a la vida. Sólo la muerte (...) permite alcanzar lo absoluto: sacrificando la vida se prueba que se amaba más al ideal que a la vida" (18).

La imagen del guerrero, es la del heroísmo humano que no teme a la muerte por amor a su cuerpo, sino que es capaz de amar más lo abstracto de su causa que el propio cuerpo que lo ata a la vida, hecho a través del cual trasciende: "El hombre asegura la repetición de la Vida al trascender la Vida por la existencia, y por medio de esa superación crea valores que niegan todo valor a la pura repetición" (De Beauvoir, 109). Así, la guerra y quienes se ocupan de ella, han sido altamente más valorados en nuestra cultura, que la capacidad de dar vida que tienen las mujeres.

Todorov se refiere a las virtudes humanas diferenciando entre las heroicas y las cotidianas. Las primeras estarían históricamente vinculadas a los hombres y serían más necesarias en tiempos de guerra, mientras que las segundas, estarían históricamente vinculadas a 
las mujeres y serían más necesarias en tiempos de paz (15). La mayor diferencia entre unas y otras es que, las primeras se relacionan con un objetivo abstracto y las segundas con personas concretas (27). Aún así Todorov se pregunta por qué entonces en tiempos de paz las virtudes heroicas continuarían siendo más valoradas socialmente, y se plantea cómo en tiempos de guerra las virtudes cotidianas son esenciales para no perder la humanidad.

Este es el caso de las mujeres guerrilleras: Trascienden sus roles hegemónicos femeninos vinculados con las virtudes cotidianas, para cumplir con las virtudes heroicas requeridas en tiempos de guerra, sin embargo es innegable que para ellas esto es un esfuerzo mayor que para sus pares masculinos puesto que deben asumir un rol diferente a ese para el que fueron preparadas, y abrazar una causa abstracta que va más allá de la parentela y amigos concretos a quienes han aprendido a cuidar por medio de las virtudes cotidianas que la división de género les ha encomendado como tarea a través del espacio privado.

Ésta división es también la separación entre las esferas pública y privada, pues mientras el heroísmo guerrillero se enmarca perfectamente en el primero de estos espacios, las virtudes femeninas se relegan al segundo y se ubican en una jerarquía inferior (Pateman, 1996).

Si algo complejiza la construcción del personaje performático de "la guerrillera", es que éstas tienen en sus manos no solo el poder de la muerte propia de quienes están dispuestos a dar sus vidas por una causa abstracta, sino también el de la vida toda vez que -participantes de la "lucha por la causa"- continúan teniendo potencialmente el don de la maternidad y no renuncian a sus vidas privadas, ámbito donde lo femenino tiene su lugar. En las guerrilleras entonces tenemos a eros y thánatos unidos, haciéndolas doblemente peligrosas e inconmensurables para el sistema sexo género tradicional (Vidaurrázaga, 2006), o -al decir de Todorov- englobando en una persona a las virtudes cotidianas y virtudes heroicas. Sobrepasan así todo molde del deber ser mujer-femenino hegemónico y evidencian la imposibilidad de llegar a ser completamente mujeres, en tanto la mujer y lo femenino (sexo y género) son ambas construcciones que responden a un fin social determinado que requiere la subordinación 
de la mujer-femenino al hombre-masculino; y de la homosexualidad frente al mandato heterosexual, siguiendo a Judith Butler (2007).

Cabe preguntarse entonces si ¿Era lo mismo para hombres y mujeres sacrificar la familia (llamado que hacía el Che)? ¿Dejar a los hijos/as es igual para las madres y los padres en el sistema sexo género dominante donde para las mujeres el ser madre es el rol esencial y naturalizado, como plantea Marcela Lagarde $(1990,362)$ o como refiere Julia Kristeva a propósito de la influencia del cristianismo y la imagen de la virgen María? (1998, 209). Porque, aun cuando el ser mujer e intentar personificar un género femenino, sean una construcción que responde a un control social, la sola crianza de estas personas (catalogadas como mujeres en el sistema sexo género dominante) les implica un deber ser femenino en el que la maternidad es el papel preponderante que da sentido a la vida.

Así se refiere el Che a este sacrificio de la familia por la revolución:

Los dirigentes de la Revolución tienen hijos que en sus primeros balbuceos, no aprenden a nombrar al padre; mujeres que deben ser parte del sacrificio general de su vida para llevar la Revolución a su destino; el marco de los amigos responde estrictamente al marco de los compañeros de Revolución. No hay vida fuera de ella $(1965,7)$.

En el mismo texto del Hombre y la Revolución en Cuba agrega:

Si un hombre piensa que, para dedicar su vida entera a la revolución, no puede distraer su mente por la preocupación de que a un hijo le falte determinado producto, que los zapatos de los niños estén rotos, que su familia carezca de determinado bien necesario, bajo este razonamiento deja infiltrarse los gérmenes de la futura corrupción. En nuestro caso, hemos mantenido que nuestros hijos deben tener y carecer de lo que tienen y de lo que carecen los hijos del hombre común; y nuestra familia debe comprenderlo y luchar por ello. La revolución se hace a través del hombre, pero el hombre tiene que forjar día a día su espíritu revolucionario $(1965,7)$.

Las guerras y las guerrillas son un mundo que en el sistema sexo género hegemónico pertenece a la díada de lo masculino-público, y 
en el que por tanto se encuentran más cómodos los hombres criados para personificar el rol masculino. Estas mujeres entonces transgreden la norma de género al participar activamente en este mundo de las guerrillas, trasvistiéndose en el papel tradicional del macho: el guerrero, y tomando para sí el poder de la muerte: thánatos. Pero al mismo tiempo son mujeres que no abandonan sus roles tradicionales femeninos, lo que puede desprenderse de sus historias de vida y se evidencia sobre todo en sus maternidades, rol por excelencia femenino y que les entrega el poder anverso al de la muerte: la vida o eros (Vidaurrázaga, 2006).

Es este doble poder en manos de estas mujeres-militantes-guerrilleras lo que desestabiliza el orden del sistema sexo género hegemónico, transgrediendo la naturalización de las mujeres encasilladas en dar la vida y como eternas promotoras de la paz. Es precisamente este doble poder el que las hace temibles y doblemente reprimibles para los aparatos de control, que no solo castigan en ellas las transformaciones radicales que pretenden en el sistema social, sino también las que se encarnan en sus propios cuerpos y acciones al tomar armas, estar decididas a matar o dar la vida por una causa, y al mismo tiempo no renunciar a papeles tradicionalmente femeninos como la maternidad.

¿El despojamiento del mundo privado-concreto para dedicarse a la lucha política-abstracta por entero fue una renuncia por igual para hombres y mujeres? ¿Tomar las armas fue para ambos igual de desconocido o presentaba diferencias aunque fuera por los juegos que realizaban desde pequeños/as? ¿La vida concreta de quienes participaron en la lucha política y armada fue igual para hombres y mujeres? ¿La mayor libertad sexual posibilitada por la clandestinidad era igual de nueva para ellas y para ellos?

Es a partir de esta moral revolucionaria en la que se desenvolvían estas militantes, que nos interesan las diferencias que emergieron entre ellas y sus compañeros de lucha política y armada. Diferencias que pueden haber provocado tensiones en ese momento o actualmente. ¿La moral revolucionaria las había incluido a ellas, o ellas se amoldaron a un concepto creado desde y para la masculinidad?

Marcela Lagarde comenta respecto del ingreso de las mujeres a procesos políticos a lo largo de la historia: 
No es el momento, es peligroso, no es conveniente, ya se resolverá más adelante. La paradoja política más dolorosa para las mujeres ha sido la entrega, por conciencia y búsqueda de justicia en el mundo y en la propia vida, a procesos que han apoyado el empoderamiento patriarcal de los hombres y el reforzamiento de escalafones y estructuras de opresión (16).

O tal vez ¿La moral revolucionaria abrió brechas de transformación que estas mujeres aprovecharon y llevaron más allá de sus límites evidenciando así la posibilidad de negar la naturalización del género femenino y la imposibilidad de responder fielmente a los mandatos que el sistema sexo género hegemónico impone a las mujeres-femeninas?

\section{El caso de las miristas}

Para trabajar este tema en relación a las mujeres miristas, contamos con escasas fuentes dado que en la mayoría de los textos que se refieren al MIR, la historia de sus militantes mujeres, pero también el acontecer de la vida cotidiana-privada de hombres y mujeres ha sido obviado ante la fuerza del actuar público-político del MIR y sus principales dirigentes varones.

Hemos utilizado para este artículo un conjunto de textos que -hablen o no de las mujeres- se refieran de alguna forma a la importancia que el MIR le daba al dejar la vida privada en un segundo plano siendo primordial la lucha por el ideal, en este caso, la revolución. Hemos tratado también con testimonios de mujeres miristas independiente de si estos tienen una perspectiva de género, entrevistas realizadas para un proyecto en desarrollo y trabajos audiovisuales que fueron hechos por mujeres y -quizás por esto mismo- apuntan al espacio privado de los miristas y permiten un enfoque más coherente con nuestras preguntas. Finalmente hemos utilizado la investigación, con perspectiva feminista, que hemos realizado como titulación de magíster y que ocupa los testimonios de tres mujeres militantes y feministas de esta organización ${ }^{1}$.

El investigador Hernán Vidal realiza en uno de estos textos una crítica a la falta de trabajos sobre la vida cotidiana de los y las miristas, en los que seguramente la participación de las mujeres estaría 
más presente y mostraría mayores niveles de contradicción con la militancia:

... estos partidos mismos no tienen una historiografía "humana", que ilumine las implicaciones de entregarse a un trabajo vivido con grandes riesgos, amenazas y peligros, abandonando familias y amigos, aislándose, sometiéndose a presiones y apremios terribles, echando mano de recursos espirituales y físicos extremos e insospechados, quizás cometiendo errores que aseguran la muerte de cientos sino de miles de personas. No sólo privan a su partido de su historia, también la niegan a la nacionalidad chilena (26).

Enrique Pérez en su testimonio, recuerda cómo eran admirados los dirigentes miristas por dejar sus vínculos concretos por dedicarse a la causa mirista, lo que evidencia la idea de sujeto revolucionario que se buscaba y admiraba dentro del MIR:

Se practicaba una moral espartana y hasta las relaciones personales se subordinaban a la vida política, cuestionando la doble moral burguesa. Admirábamos a nuestros dirigentes, que son capaces de renunciar a sus orígenes pequeño burgueses y a la vida formal de pareja o familia para abrazar la causa revolucionaria (64).

En su texto sobre el MIR el historiador Carlos Sandoval, quien además fue militante mirista, recuerda las exigencias de la militancia: "Por ello que no había descanso, no había posibilidad de distracciones ni de placeres 'pequeño burgueses'; todo había que darlo por la Revolución, todo el tiempo vital había que dedicarlo a la construcción y expansión no sólo del MIR, sino, sobre todo de sus políticas" (93).

Y más adelante recuerda una situación en la que no pudo llorar. ¿Cómo habrá funcionado esta orden inconciente de no llorar para el caso de las mujeres que se autocalificaban de revolucionarias con toda la carga moral de este concepto en la época?: "Me acuerdo que no pude llorar 'porque los hombres no lloran', menos lo podía hacer un revolucionario: para nosotros estaba reservado sólo 'tomar la bandera del compañero caído y seguir la marcha'" (97).

En entrevistas, ex militantes miristas recuerdan cómo el MIR exigía una dedicación total, que era tanto para los militantes como 
para ellas: Porque primero el partido, segundo el partido y tercero el partido (Álvarez, 11).

Siempre con un $100 \%$ de entrega a lo social, descuidando (autocríticamente te lo digo) el aspecto no solamente familiar, sino que el cuidado de uno mismo, por que eso nos pasa a todos nosotros: no tenemos tiempo de ir al médico, no tenemos tiempo de hacernos exámenes y se ha ido muriendo la gente, no llega a los 65 años (Goñi, 3)

Había que creer en los postulados del MIR, tener el convencimiento de querer trabajar, entregar su tiempo, porque yo pasaba matiné, vermut y noche con el MIR, trabajamos en las poblaciones, fabricas, estudiábamos, íbamos a reuniones, era una vida consagrada al MIR. (Brito, 2)

El propio Miguel Enríquez, dirigente máximo de la entidad, señala en sus notas sobre la formación de cuadros cómo el militante debe ser un sujeto ejemplar tanto en la vida pública como privada y da luces sobre la idea del hombre nuevo del Che:

El militante revolucionario debe observar las mismas normas de comportamiento en la actividad política como en la vida privada. En todo momento debe representar el ejemplo vivo de una nueva moral, prefigurando el futuro ser humano integral de la sociedad socialista $(1974,24)$.

Lo que se requería para ser un militante ejemplar, se exigía por igual para hombres y mujeres, independiente de la crianza sexo genérica con la que cada uno llegaba a la militancia, según el testimonio de Lucrecia Brito: "Se nos exigía igual, íbamos a la misma escuela de cuadros, teníamos la misma formación militar, habían mujeres que tenían cargos militares igual que los hombres o que en esos ámbitos eran mucho mejores que los hombres" (5).

En un documento posterior a 1973 y realizado como evaluación tras la constante caída de militantes, la dirección del MIR señala la importancia de controlar con rigor no solo las vidas públicas sino también las cotidianas, para evitar futuras caídas (Enríquez, 345). Esta necesidad de control de lo cotidiano, que podía operar como un espacio peligroso sino se operaba en este espacio con el máximo 
rigor, se entiende cuando Todorov se refiere a lo solitario de la calidad del héroe: "El héroe es un ser solitario, y ello por un doble motivo: por un lado combate por abstracciones más que por individuos; por otro, la existencia de seres cercanos le hace vulnerable" (16). Es precisamente esta vulnerabilidad la que trataba de evitarse obviando las vidas privadas de los y las militantes. ¿Pero era igual para hombres y mujeres evitar pegar en la pared el dibujo de un hijo o hija?

En el texto de Nubia Becker, mirista, apodada Carmen Rojas para la edición de su libro testimonial, habla del machismo como una forma de descalificar cuando se refiere a tres compañeras que están colaborando con la DINA: "Las tres, aparte de ser colaboradoras, eran repelentes, neuróticas, resentidas y tremendamente machistas" (42).

Otro momento en que se evidencia la molestia desde el poder a la trasgresión de las mujeres militantes es cuando se refiere a la frase pronunciada por el agente Conrado Pacheco refiriéndose a las mujeres que estaban detenidas: "La mujer no es para estas cosas. Porque yo siempre he dicho que cuando sale sola, ya cuando vuelve no es nunca la misma..." (Rojas, 86).

Aunque el relato es subjetivo y personal, se centra en un tiempo en el que es difícil evidenciar diferencias o tensiones de género entre hombres y mujeres militantes, pues es una experiencia excepcional, sobre todo la tortura y detención en Villa Grimaldi. Asimismo, y a pesar de haber sido escrito por una mujer, no son estas diferencias lo que a la protagonista le interesa relevar, sino más bien la denuncia de las represiones, y la continua autoafirmación de que lo importante en esa situación era no quebrarse ni entregar a los compañeros, no traicionar. Este, es uno de los motivos principales y reiterados del testimonio.

Quince años después, el 2001, nos encontramos con el libro inédito y testimonial de Arinda Ojeda, De Memoria, presa política de la fase del retorno mirista ${ }^{2}$, quien en su relato muestra constantemente las tensiones de género, con una crítica feminista evidente hacia las órdenes y estructuras partidarias. En este libro, Arinda se refiere a las diferencias entre hombres y mujeres militantes, habla también de cómo constantemente tenía que estar probando su valor, y cómo la elección de dejar a su hijo en el Proyecto Hogares ${ }^{3}$ le significo una 
serie de desgarros y tensiones adicionales por el hecho de ser una mujer y no un hombre. Señala:

\begin{abstract}
Recordaba las largas conversaciones con la Pity. Mientras sus dos pequeños y el mío jugaban alegremente a nuestro alrededor. Entonces la vuelta no era inminente pero ya se dibujaba en nuestro futuro y hablábamos y hablábamos de cómo sería separarse de los hijos, que una vez hecho no habría vuelta atrás. Y nos dábamos ánimos sabiendo bien que cada una sería la prueba más difícil de enfrentar, pues aunque la cabeza lo entendía, el corazón nunca aprendería a sobreponerse. Ahora lo estaba viviendo y podía tomar conciencia de que todo lo dicho en aquel tiempo se quedaba corto frente a la realidad (11).
\end{abstract}

Asi mismo describe las agresiones físicas y verbales que recibió en la tortura y que evidenciaban la molestia de los agentes de seguridad ante la transgresión de ella a la norma tradicional de las mujeres:

Allí el ogro me recuerda que le mordí la mano y se toma su revancha despellejando mi pubis a tirones. Los otros también quieren sus pequeñas venganzas ¿de qué? Poco importa. Empiezo a entender que los motivos sobran, seguiré entendiéndolo en las sucesivas sesiones: ser mujer, estar metida en cosas de hombres, es una de las recurrentes causas para el castigo (81).

En otra orilla encontramos textos investigativos críticos al analizar los testimonios, entre los cuales está Mujeres en Rojo y Negro. Reconstrucción de memorias de tres mujeres miristas 1970-1989 (Vidaurrázaga, 2006).

En esta investigación, nos pareció que si bien el MIR era un espacio que replicaba las normas tradicionales del sistema sexo género para lo femenino y lo masculino, al mismo tiempo abría brechas a través de las cuales las militantes se empoderaron -al darse cuenta que tenían la misma capacidad en la lucha que los varones- y tenían cierto discurso revolucionario que permitió el nacimiento de prácticas y discursos feministas, ya sea conscientes o de hecho, dentro de sus filas. 
Al mismo tiempo descubrimos tensiones entre las militantes entrevistadas en tanto sus emancipaciones como mujeres y el deber de la militancia; y entre sus maternidades y el espacio de la militancia para lo privado que en general era escaso o inexistente, dadas las normas de seguridad que había que seguir, como señalaba Miguel Enríquez ${ }^{4}$.

Uno de los periodos en que estas tensiones entre ser mujeres y las exigencias partidarias fue más evidente, por tratarse de un espacio eminentemente masculino, es en la escuela de guerrilla en Cuba, donde una de las militantes recuerda:

Eso significaba que tenía que meterme al mundo de los hombres y competir con ellos, no llegar a ser físicamente como ellos, porque eso ya es mucho pedir, pero sí hacer un gran esfuerzo por estar a la altura. (...) En lo que era más complicado de todo, era en el tema de la competencia, era como que si tú te habías metido al mundo de los hombres, no podías después echarte para atrás, ya tenías que apechugar no más. Y los hombres te tenían el ojo puesto encima, te lo tenían puesto (Aránguiz en Vidaurrázaga 276-277).

En las relaciones de pareja, donde especialmente la clandestinidad y la premura de vivir con la muerte a cuestas significó una variedad más amplia de relaciones contingentes, éstas no eran igual de evaluadas en las mujeres que en los varones miristas:
(...) obviamente que había más discriminación, es que nunca po- día ser igual. Por ejemplo si la compañera tenía a su pareja en La Habana y estaba empezando otra relación por acá, no iba a haber la misma reacción, hasta alguien se le podía acercar y decirle, pero si era un compañero nadie se iba a acercar a decirle algo (Aránguiz en Vidaurrázaga 278).

Otro momento en que las tensiones entre las exigencias militantes y las exigencias de la feminidad tradicional se hicieron punzantes, fue en la época de la Operación Retorno, cuando los hombres comenzaron a volver y luego las mujeres quisieron ser parte de la resistencia que se rearmaba en Chile, para lo cual debían tomar la decisión de dejar a los hijos al cuidado de otros, o sea renunciar a sus maternidades tradicionales en pos de la revolución: 
Claro porque cuando se venía un compadre a Chile, atrás, quedaba una mujer haciéndole señas y un cabro chico agarrado a la falda gritando por su papito. Y cuando se venía uno nadie consolaba el cabro chico y había que apagar la luz y cerrar la puerta. Además había que demostrar porque se venía. Nadie nos decía que debíamos ponernos 10 kilos más en la mochila, pero había que hacerlo para demostrar por qué una se venía (Ojeda en Vidaurrázaga 242).

Beatriz Álvarez, ex mirista, recuerda en una entrevista la diferencia respecto de los hijos para hombres y mujeres miristas: “O sea, la tarea de la maternidad abarcaba exclusivamente a la mujer. El hombre: ¡Chao! tu eres un revolucionario, libre sin hijos, sin nada” (13).

Dejar a los hijos fue una de las decisiones más brutales vividas por las mujeres militantes del MIR, quienes en esta decisión probaban literalmente si estaban dispuestas a dejarlo todo por el abstracto de la revolución. O como diría Todorov, probar que primaron las virtudes heroicas por sobre las cotidianas, en mujeres criadas por el sistema sexo género para cumplir precisamente con las virtudes cotidianas.

Y empezar a decir sí, yo creo en la justicia, creo en la igualdad, yo creo en el MIR, creo en las cosas que levanta el MIR, creo en que hay que irse a Chile a pelear, y soy mamá, y eso es fuerte, pero yo también soy esa otra, y tengo que reconocerlo en mí y darme cuenta que es tan importante como esto otro. No es una cosa antes que la otra, son conjuntas, paralelas. No puedo ser la pura mamá y dejas de ser la militante que ahora me doy cuenta que soy, ni al revés, ser la pura militante y decir que no me importa lo que pase. Soy las dos, pero las dos me importan y las dos no pueden dejar de ser. Y tengo que buscar un punto intermedio, algo más o menos equilibrado que no me signifique sacrificar absolutamente a ninguna de las dos, como cosa estratégica, porque igual había renuncias que iban a ser temporales, en este caso el tema de la maternidad (Aránguiz en Vidaurrázaga, 247-248).

En una entrevista a Adriana Goñi, ex mirista, reflexiona sobre su maternidad en medio de la militancia mirista denotando que la tensión respecto de las maternidades puestas en un segundo lugar implican consecuencias hasta el día de hoy: "Ahora, si tú 
me preguntas ¿cómo lo hacía yo como mujer? No, los resultados están a la vista, mis hijos se criaron solos y tienen conciencia de eso y me lo echan en cara todos los días" (15).

En el documental El edificio de los Chilenos (Aguiló, 2010), se narra la historia de los niños y niñas que fueron dejados en Cuba en el Proyecto Hogares del MIR, y en las tensiones y cuestionamientos que esta decisión produce hoy en los adultos en que se convirtieron estos infantes, y también en los adultos militantes que entonces tomaron la decisión. Si bien el trabajo no pretende tener una perspectiva de género, es interesante escuchar lo que dicen las mujeres respecto de cómo tomaron la decisión, y sobre todo de cómo impulsaron este proyecto en la idea de que ellas también querían participar del retorno y buscaron una solución colectiva para resolver el cuidado de los/as niños/as, un experimento interesante que pone el MIR no solo en el plano de las decisiones políticas sino en las decisiones morales y privadas de sus militantes, lo que a todas luces nos parece interesante tanto desde una perspectiva feminista, como de género, especialmente al observar cómo las decisiones militantes influían en la vida privada de los miembros/as del partido, y cómo éste tipo de decisiones tensionó especialmente a las mujeres, quienes debieron optar entre la urgencia de la militancia y la de la maternidad. Una de las dos debió, al menos, aplazarse, y esa sería una decisión que pesaría para el resto de sus vidas.

\section{Palabras finales}

La revolución abstracta por sobre la concretitud de la vida misma, esa es la elección que hacen quienes se "entregan" por completo a la causa revolucionaria. Las virtudes heroicas sobrepasan con creces a las cotidianas, que en ocasiones incluso se olvidan o relegan a un último plano. Todo sea por cumplir con las normas de la moral revolucionaria, que -en el caso de las organizaciones guevaristas como fue el MIR- se vinculaba con que cada ser humano se convirtiera en el llamado hombre nuevo.

¿Pero este hombre nuevo se construyó como concepto pensando en las experiencias de vida de ambos géneros? ¿Lo femenino y lo masculino y a su vez los hombres y mujeres estaban ambos contemplados en este ideal de persona? ¿Cuándo personajes como el Che Guevara 
daban consejos de cómo hasta la familia debía ser secundaria por la revolución, tomaron en cuenta lo que esto significaba para el caso de las mujeres que habían crecido con el mandato sexo genérico de ser madres ante todo?

Creemos que no, que el hombre nuevo no por nada se llamaba hombre y no humano, y que al construirse como ideal revolucionario tomó en cuenta a quienes históricamente han liderado las revoluciones: los varones. Las mujeres que quisieron ser parte de una revolución que no las incluía de antemano debieron adaptarse a este sujeto como si fuera neutro, aunque en verdad no lo era. Y para ello saltaron zanjas aún más profundas que las de los varones, que de por si dieron grandes zancadas para ser lo que exigía la revolución, alejado de la humanidad verdadera a la que Todorov se refiere con las virtudes cotidianas.

Estas mujeres evidentemente se encontraron con los pies puestos en dos zonas diferentes y alejadas: una la de la guerrillera heroica, sacrificial, ejemplar y dispuesta a morir o dejar a sus hijos por esos otros hijos "abstractos" que por medio de la revolución se volvían propios. Otra, en la zona de seguridad que tenían antes de hacerse guerrilleras, donde cumplían con los mandatos del sistema sexo género y en la cual ser madres era el valor más grande de sus vidas. En ambas orillas había un poco de mandato y poco de voluntad, y sin embargo ambas eran contradictorias y difíciles de vivir a un tiempo.

No sabemos cuán difícil fue para una y otras, sin embargo es seguro que para ellas salirse de sus roles históricos significó doble trabajo que para sus compañeros varones. El hombre nuevo nunca estuvo pensado para las mujeres, ni para la multiplicidad de humanidades participantes del proyecto revolucionario y, finalmente -cuando la revolución fracasó y quedó la vida cotidiana prevaleciendo- seguramente también fueron ellas las que pagaron los costos más altos por las elecciones que tomaron cuando la revolución era todo en sus vidas. Una pregunta que se presenta incipiente pero potencialmente fructífera es la que plantea Carmen Castillo a una de sus entrevistadas Margarita Marchi, también mirista, en el documental Calle Santa Fe: “Por qué tuvimos hijos?” (2005). Quizás es esta pregunta la que mejor evidencia los costos que tuvo para las mujeres ser parte de una revolución que nunca las incluyó en toda su dimensión. 


\section{Notas}

1 Ver en bibliografía apartado de corpus para conocer en detalle el material con el que se trabajó la idea de moral revolucionaria en el MIR y la situación de las mujeres miristas.

2 EL MIR comenzó una política sistemática de retorno alrededor de 1978, la cual consistía en que militantes previamente adiestrados en una escuela de guerrrilla en Cuba retornaran clandestinos a la resistencia en Chile. En este contexto fue un tema entre los y las militantes -cuando había descendencia- quien se quedaba con los pequeños/as.

3 Proyecto llevado a cabo por la dirigencia mirista que consistió en destinar un grupo de militantes dedicados a ser padres o madres sociales de un colectivo de unos 60 a 80 niños y niñas cuyos padres y madres los dejaron primero en Europa y luego en Cuba, para retornar clandestinamente a la lucha en Chile a fines de los 70 .

4 Sin embargo, el mismo Enríquez no operaba con estas normas de seguridad y vivía clandestino compartiendo casa con su hija y la hija de su pareja Carmen Castillo, lugar donde cayó baleado.

\section{Bibliografía}

Aguiló, Macarena.El edificio de los Chilenos. Documental Aplaplac Producciones, 2010.

Belli, Gioconda. El país bajo mi piel. Barcelona: Plaza \& Janés, 2001.

Butler, Judith. El género en disputa. Barcelona: Ediciones Paidós, 2007.

Castro, Fidel. "Discurso en el acto de Katowice el 7 de junio de 1972". En El futuro es el internacionalismo. La Habana: Instituto Cubano del Libro, 1972.

Castillo, Carmen.Calle Santa Fe. Documental Parox (Chile)-Les Films D'ici (Francia)Les Films de la Pasarel (Bélgica), 2007.

De Beauvoir, Simone. "El segundo Sexo". En La experiencia vivida. Buenos Aires: Siglo XX, 1987.

Debray, Regis. "Revolución en la revolución". En Punto Final, n 25, 2ª quincena de marzo de 1967, Santiago, Chile.

El Pensamiento Revolucionario del "Che" Seminario Científico Internacional. Intervenciones y debates 1988. Buenos Aires: Editorial Dialéctica. Colección Política y Sociedad.

Enríquez, Miguel. Con vista a la esperanza. Santiago: Escaparate Ediciones, 1998.

Guevara, Ernesto. "El socialismo y el hombre en Cuba". En Marcha, Montevideo, 1965, versión electrónica tomada de Ernesto Che Guevara, Escritos y discursos, Tomo 8. La Habana: Editorial de Ciencias Sociales, 1977.

"El socialismo y el hombre en Cuba", Obras, tomo II, 374. En El Pensamiento Revolucionario del "Che" Seminario Científico Internacional. Intervenciones y debates 1988. Buenos Aires: Editorial Dialéctica. Colección Política y Sociedad, 1989.

Kristeva, Julia. “Sabat Mater". En Historias de amor. México: Siglo XXI, 1988. 
Lagarde, Marcela. Madresposas, monjas, putas y locas. Estudios de los cautiverios femeninos. México: Universidad Autónoma de México, 1990.

------. "Claves Identitarias de las Latinoamericanas en el umbral del milenio". En Ana María Portugal y Carmen Torres (editoras). El siglo de las mujeres. Santiago: ISIS Internacional, 1999.

Martínez, Heredia Fernando. "Che, el socialismo y el comunismo". En Pensar al Che. La Habana. José Martí, 1989.

Ojeda, Arinda. De memoria. Concepción, 2001 (inédito).

Pérez, Enrique. La búsqueda interminable. Diario de un exiliado politico chileno en Suecia. Santiago: Mosquito Editores, 1996.

Rojas, Carmen. Recuerdos de una mirista. Montevideo: Del Taller, 1988.

Ruiz, María Olga (Investigadora responsable). Entrevistas a Adriana Goñi, Beatriz Álvarez y Lucrecia Brito, realizadas en la investigación en desarrollo "La risa y la vergüenza. Sobrevivir a la experiencia concentracionaria en los centros clandestinos de tortura y campos de detención en Chile, Argentina y Uruguay" (VID/UCH).

Sandoval, Carlos. Movimiento de Izquierda revolucionaria 1970-1973 - Coyunturas, documentos y vivencias. Concepción: Escaparate Ediciones, 2004.

Todorov, Tzvetan. Frente al límite. México: Siglo XXI editores, 2009.

Vidal, Hernán. Presencia del MIR. 14 claves existenciales. Chile: Mosquito editores, 1999.

Vidaurrázaga, Tamara. Mujeres en Rojo y Negro. Reconstrucción de memoria de tres mujeres miristas: Santiago. Escaparate, 1996. 
